\title{
Quantitative assessment of LV function and volumes with 3-slice segmentation of cine SSFP short axis images: our experience
}

Edward Kuoy ${ }^{1 *}$, Christopher V Nguyen ${ }^{1}$, Sumudu N Dissanayake ${ }^{3}$, Kari J Nelson², Pablo J Abbona ${ }^{2}$, Mayil S Krishnam²

From 17th Annual SCMR Scientific Sessions

New Orleans, LA, USA. 16-19 January 2014

\section{Background}

Cardiac MRI is the gold standard for assessing cardiac function, but requires contour tracing of the left ventricular (LV) myocardium through multiple cine steadystate free precession (SSFP) short axis images. Despite advancements in semi-automated software, contour detection and manual readjustments of multiple slices throughout the cardiac cavity remains a tedious process. Our goal is to assess LV functional parameters using 3slice segmentations in comparison to conventional multi-slice segmentation in patients with a wide range of pathologies.

\section{Methods}

We retrospectively studied $1.5 \mathrm{~T}$ cardiac MR images of 62 patients with various clinical indications. All patients had a stack of EKG gated segmented SSFP cine images through the LV. Semi-automated cardiac MR software (Argus) was used to trace LV contours both at multiple slices from base to apex as well as just 3 slices (base, mid and apical) by two readers. End diastolic volume (EDV), end systolic volume (ESV), stroke volume (SV), and ejection fraction (EF) were calculated using both assessment methods.

\section{Results}

There were no statistically significant differences between $\mathrm{EF}$ and LV volumes obtained by multi-slice vs 3 -slice analysis for both readers $(P>0.05)$. For reader 1 (and 2), Bland-Altman plot revealed the mean difference in LVEF between multi-slice and 3-slice analysis was $0.4 \%(0.5 \%)$ with limits of agreement of $-4.3 \%$ to $5.1 \%(-3.9 \%$ to $4.9 \%)$ (Figure 1). For both readers, all differences in EF between multi-slice and 3-slice analysis were within 5.3\%. The measured volumes are listed in Table 1. Multi-slice assessment required approximately 10 minutes per study while 3-slice evaluation required about 3-5 minutes.

\section{Conclusions}

The LVEF obtained from either 3-slice or multi-slice evaluation of SSFP cine images closely correlate across various cardiac pathologies, thereby offering a method to reduce post-processing time. Of note, although the decreased LV volumes obtained by 3 -slice segmentation are statistically significant, the difference of $<3.7 \%$ may not be clinically significant.

\section{Funding}

None. 
(a) Reader 1: Multi-slice vs 3-slice EF

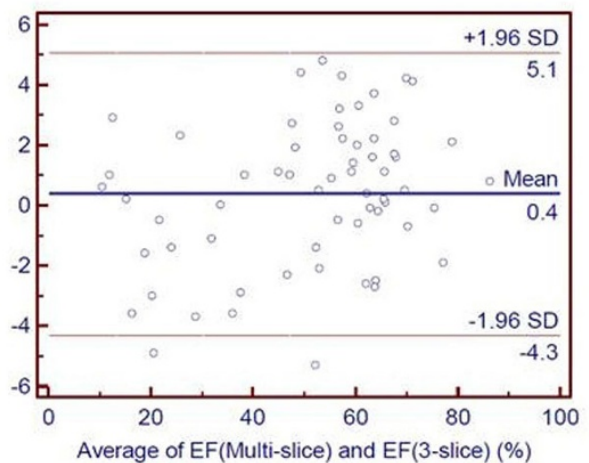

(b) Reader 2: Multi-slice vs 3-slice EF

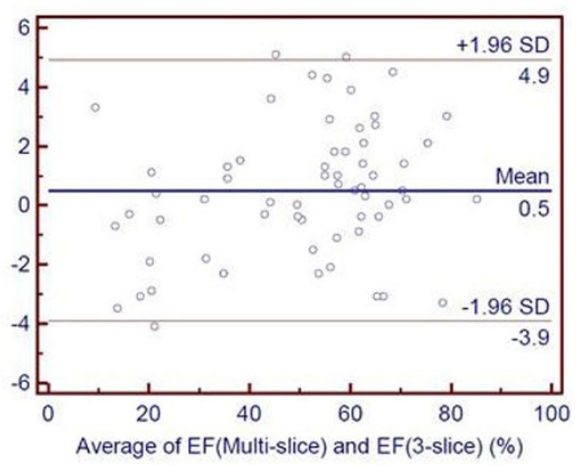

Figure 1 Bland-Altman Plots for evaluation of the differences between ejection fraction (EF) measurements using multi-slice and 3-slice slice technique for (a) Reader 1 and (b) Reader 2.

Table 1 Left Ventricular Functional Parameters

\begin{tabular}{cccccc}
\hline & Reader 1 (3-slice) & Reader 1 (multi-slice) & Reader 2 (3-slice) & Reader 2 (multi-slice) & p-value \\
\hline$E F(\%)$ & $50.8+/-18.8$ & $51.2+/-19.5$ & $50.3+/-18.7$ & $50.8+/-19.3$ & $p>0.05$ \\
\hline$E D V(m L)$ & $112.9+/-55.7$ & $117.0+/-59.3$ & $113.7+/-54.1$ & $118.1+/-57.2$ & $p>0.05$ \\
\hline$E S V(m L)$ & $63.7+/-57.3$ & $66.0+/-61.4$ & $64.1+/-55.6$ & $66.5+/-59.1$ & $p>0.05$ \\
\hline$S V(m L)$ & $49.3+/-17.1$ & $51.1+/-17.7$ & $49.6+/-16.9$ & $51.6+/-17.6$ & $p>0.05$ \\
\hline$C O(L / m i n)$ & $3.5+/-1.6$ & $3.6+/-1.7$ & $3.5+/-1.6$ & $3.7+/-1.7$ & $p>0.05$ \\
\hline
\end{tabular}

\section{Authors' details}

'School of Medicine, University of California, Irvine, Orange, California, USA. ${ }^{2}$ Cardiovascular and Thoracic Imaging, Radiological Sciences, University of California, Irvine, Orange, California, USA. ${ }^{3}$ Radiology, University of California, Irvine, Orange, California, USA.

Published: 16 January 2014 and volumes with 3-slice segmentation of cine SSFP short axis images: our experience. Journal of Cardiovascular Magnetic Resonance 201416 (Suppl 1):P384.

Submit your next manuscript to BioMed Central and take full advantage of:

- Convenient online submission

- Thorough peer review

- No space constraints or color figure charges

- Immediate publication on acceptance

- Inclusion in PubMed, CAS, Scopus and Google Scholar

- Research which is freely available for redistribution 